\title{
Newborn Motor Scale
}

National Cancer Institute

\section{Source}

National Cancer Institute. Newborn Motor Scale. NCI Thesaurus. Code C81270.

A range of values used to quantify newborn motor development. 